\title{
О ДЕМОГРАФИЧЕСКОМ РАЗВИТИИ СТРАН БРИКС Заметки с Цивилизационного форума «Перспективы и стратегические приоритеты восхождения БРИКС»
}

\author{
АЛЕКСАНДР ТКАЧЕНКО
}

\begin{abstract}
В статье рассмотрены итоги Цивилизаџионного форума «Перспективы и стратегические приоритеты восхождения БРИКС», на котором обсуждался доклад к предстоящуему в 2015 г. в Уфе VII саммиту стран БРИКС. Автор остановился на двух проблемах, занявших основное место 6 изданном докладе и выступлениях: демографического прогноза по странам БРИКС до 2100 г. и идеи противопоставления нисходящзей (западной) и восходящей (восточной) цүивилизаций. Модели роста численности населения, представленные на форуме, носят слишком условный характер, не касаются миграции и содержат рекомендаџии правительствам двух крупнейтих стран мира. Индии угрожает возможность превысить экологически допустимую ёмкость территории при сохранении существующих темпов прироста населения. Китаю, напротив, необходимо, увеличить рождаемость для решения проблемы постарения населения и уменьшения доли трудоспособного населения после 2050 г. Эти и ряд других идей доклада противоречат, по мнению автора статьи, современным идеям демографической науки.
\end{abstract}

Ключевые слова: БРИКС как геоцивилизационный союз, демографические прогнозы, мировые циивилизации, ожидаемая продолжительность жизни, геополитический потенциал, человеческий капитал, производительность труда.

17 декабря 2014 г. в Москве (зал Ученого совета в Научной библиотеке МГУ им. М.В. Ломоносова) состоялся IX Цивилизационный форум «Перспективы и стратегические приоритеты восхождения БРИКС», который собрал представителей всех стран этой группы для обсуждения доклада к предстоящему в 2015 г. в Уфе (Башкортостан, Россия) ежегодному VII Саммиту стран БРИКС. Доклад издан в виде фундаментальной монографии с тем же названием, в создании которой принимал участие большой коллектив ученых России [Перспективы... 2014].

Помимо МГУ, в основном в лице факультета глобальных процессов, в организации форума приняли участие 4 научных института (Институт экономических стратегий, Международный институт Питирима Сорокина - Николая Кондратьева, Институт Латинской Америки РАН, Институт Дальнего Востока РАН) и Национальный комитет по исследованию БРИКС. Форум был организован таким, скажем, особым образом, что в обсуждении доклада принимали участие только сами его авторы.

\footnotetext{
АЛЕКСАНДР АЛЕКСАНДРОВИЧ ТКАЧЕНКО, ФИНАНСОВЫЙ УНИВЕРСИТЕТ ПРИ ПРАВИТЕЛЬСТВЕ РФ. РОССИЯ. E-MAIL: AATkachenko@fa.ru
}

СТАТЬЯ ПОСТУПИЛА В РЕДАКЦИЮ В ДЕКАБРЕ 2014 Г. 
Форум и его результаты не могут не привлечь внимание демографовпрофессионалов и всех интересующихся демографическими проблемами по нескольким причинам. Во-первых, как основной научный доклад, изданный в виде книги, так и основной устный доклад «Математическое моделирование и прогнозирование динамики стран БРИКС до 2050 года», с которым выступил иностранный член РАН А.А. Акаев, содержали прогнозы демографической динамики мирового населения и населения стран БРИКС. Во-вторых, многие выступавшие на форуме говорили о демографических проблемах своих стран, успешности или не успешности демографической политики (как по ограничению рождаемости, так и пронаталистской), и их взгляды заслуживают внимания специалистов. В-третьих, само необычное объединение стран под названием «БРИКС» состоит из крупнейших государств мира или соответствующих континентов: крупнейшей страны Латинской Америки (Бразилия, около 200 млн человек), крупнейшей европейской страны (Россия, 144 млн), самой небольшой по населению из стран группы и пятой по численности населения Африки (Южно-Африканская Республика, 53 млн) и двух крупнейших стран мира и Азии (Китай и Индия, 1367 и 1278 млн человек соответственно). Стоит подчеркнуть, что на форуме также присутствовал и выступил посол Индонезии в РФ, большой по численности населения страны Азии (четвертая страна мира по численности населения - 253 млн человек), добившейся значительного прогресса в снижении рождаемости, который, подчеркнув роль Азии в целом в мировом развитии, сказал, что его страна с большим интересом смотрит на демографический опыт таких стран БРИКС, как Индия и Китай.

Каков же этот опыт? В своем докладе академик Акаев говорил о стабилизации численности населения Земли около 2050 г. (9,1 млрд человек) по одному сценарию или ее снижении до 5,2 млрд человек к 2050 г. с дальнейшей стабилизацией численности подругому. Было сказано о лимите демографической емкости Земли или биосферы, а по отношению к Китаю и Индии докладчик говорил о необходимости рассматривать пределы численности населения этих стран в соответствии с лимитом экологической емкости. Как ни удивительно, отечественная группа исследователей, как в МГУ, так и в институтах РАН, не уделяет должного внимания популяционно-демографической емкости нашей планеты в целом и как понятию, которое позволяет связать емкости территорий, оптимальную численность населения (демографический оптимум), популяционную емкость среды обитания (по отношению к человеку) и другие близкие понятия [Демографическая энциклопедия 2013: 280]. Политику, проводимую Китаем, докладчик назвал грамотной, а Индией - неудачной. К сожалению, регламент форума не предусматривал вопросов докладчикам и какой-либо дискуссии, поэтому осталось нераскрытым, что же понимать под грамотной политикой: жесткие экономические санкции по отношению к нарушившим предел числа детей в городской семье до 2011 г. или новую более мягкую политику китайского правительства, начиная с 2007 г. и особенно с 2013 г.? Будущее человечества, в том числе стран БРИКС, по мнению Акаева, будет определять динамика двух индикаторов: демографического (численность населения) и производительности труда; делая этот вывод, академик Акаев сослался на работы Дж. О`Нила.

В свое время термин «страны БРИК» появился с целью выделения лидеров роста и крупнейших по объему ВВП стран мира в сравнении с другими мировыми экономическими 
центрами (США, Евросоюзом и Японией). На саммите в Китае $(2010$ г.) к этим быстрорастущим экономикам присоединилась Южно-Африканская Республика, и объединение превратилось в БРИКС.

Теперь БРИКС - это 45\% населения планеты, половина всего мирового прироста ВВП в XXI веке и более четверти его мирового объема. Но в докладе [Перспективы... 2014] эти страны рассматриваются прежде всего не с точки зрения их экономических позиций в глобальной экономике, а как геоцивилизационное объединение нового типа. По мнению авторов доклада, БРИКС не может содействовать воссозданию биполярной структуры мира. Значительная противоречивость содержится, на наш взгляд, в новом «цивилизационном» подходе авторов к проблемам глобального мира и месту в нем стран БРИКС. С одной стороны, они считают, что правы исследователи, подчеркивающие, что страны БРИКС - это разные социально-экономические модели и разные цивилизации [Перспективы... 2014:46], а с другой - утверждают, что «исторический маятник» в XXI веке сохранит и усилит движение на восток и называют Восток в целом восходящей цивилизацией. «Демографические, природно-ресурсные и экономические преимущества Востока со временем будут дополнены технологическими и социокультурными и обеспечат геополитические преимущества» [Перспективы... 2014:107]. При этом из 12 выделенных авторами цивилизаций семь относятся к восходящим (объединяя их термином «восточная»), а пять - к нисходящим цивилизациям - «западная».

Все классики цивилизационных исследований выделяли китайскую (синскую), индуистскую и исламскую цивилизации независимо от их общего числа: от 7-8 у С. Хантингтона до 23 у А. Тойнби. О какой цивилизации в таком случае идет речь в парадигме «восхождения» восточной цивилизации и нисходящей цивилизации Запада? Можно ли в едином геоцивилизационном пространстве, как выражаются авторы доклада, объединять мусульманскую Индонезию и синский Китай? Но самый каверзный вопрос, на который никаких ответов пока не прозвучало: а где место России в этой парадигме «восходящих нисходящих» цивилизаций? Чем Россия ближе к Востоку по сравнению с Польшей, которую авторы относят к восточноевропейской нисходящей цивилизации Запада? Если брать за основу концепт Л.Н. Гумилева, то Россия, прошедшая тысячелетний путь развития, есть цивилизация умирающая. Тем более что и по одному из двух показателей, на примере которых авторы решили рассмотреть тенденции демографической динамики, Польша к 2050 г. потеряет меньше населения, чем Россия. В целом раздел демографической динамики представляется весьма уязвимым не столько по причине анализа, основанного лишь на динамике общей численности населения и среднем возрасте, сколько по выводам, основанным на прогнозах изменения этих показателей в 2050-2100 гг. Почти ежегодная корректировка прогнозов ООН (World Population Prospects) показывает зыбкость столь долгосрочных прогнозов, и не исключено, что, дожив до 2020 г., авторы обнаружат, что выводы на основе прогноза пересмотра 2020 г. окажутся совсем другими, нежели выводы, сделанные на основе пересмотра 2012 г. (2012 Revision).

Вернемся к устным выступлениям авторов доклада. А.В. Коротаев (Институт востоковедения РАН) в своем докладе о математическом моделировании и сценарном прогнозировании демографического будущего России остановился на переломе тенденций в демографической ситуации, которые позволили изменить прогноз численности населения 
страны со 100 млн (прогноз середины 2000-х годов) до 130 млн человек (прогноз 2013 г.) в 2050 г. Этот перелом он связывает с демографической политикой, проводимой с 2005 г., правда, временами он называет ее семейной политикой, видимо не чувствуя различий этих двух политик. После 2005 г. Российская Федерация достигла, по мнению автора, «колоссальных успехов» в снижении смертности. При этом автор анализировал только общий коэффициент смертности и даже позволял себе применять его при сравнении с другими странами БРИКС, несмотря на огромные различия в возрастной структуре. Особенно неожиданным оказался общий вывод докладчика, что снижение смертности произошло «почти исключительно» за счет роста ожидаемой продолжительности жизни. А.В. Коротаев выступает также автором раздела 4.2. письменного доклада «Опыт прогноза развития стран БРИКС» [Перспективы... 2014:260-276], посвященного только двум составляющим в каждой стране: демографическому и экономическому прогнозам. Первый дается только по общей численности населения и опирается на анализ динамики суммарного коэффициента рождаемости - СКР (не по всем странам) по 2010 г., второй только по ВВП. Автор считает, что, хотя Бразилия только недавно завершила демографический переход (нам это не представляется точным, исходя из уровня младенческой смертности, по которому Бразилия даже «опережает» Китай: 13,9 на тысячу новорожденных по сравнению с 12,6), СКР уже опустился «ниже уровня простого замещения поколений» [Перспективы... 2014:260]. Это автор считает самой серьезной проблемой в не столь отдаленном будущем и поэтому предлагает руководству Бразилии предпринять целенаправленные меры по поддержке рождаемости. Подобное предложение (отказ от ограничения рождаемости) дается в главе и по Китаю на том основании, что при сохранении нынешних тенденций убыль численности трудоспособного населения (вероятно, автор имеет в виду население трудоспособного возраста) составит к 2100 г. 400 млн человек. Также нам непонятно, почему для страны, взрослое население которой составляет около 1 млрд человек, 30 млн возможных по прогнозу к 2025 г. «безнадежных холостяков» нужно называть астрономической цифрой [Перспективы... 2014: 274]. СКР в Китае автором не рассматривается, хотя там он ниже, чем во всех странах БРИКС, кроме России. По ЮАР демографический и экономический прогнозы объединены, а прогноз динамики численности населения дается почему-то не по данным ООН, а «по Капице» [Перспективы... 2014: 277]. Демографический прогноз по Индии дает два сценария ООН (верхний и средний), а также «Иранский сценарий». Среди идей самого автора стоит выделить одобрение снижения СКР ниже уровня простого воспроизводства для «преодоления колоссальной демографической инерции, накопленной на первой фазе демографического перехода» [Перспективы... 2014:270].

И, наконец, Россия. Здесь автор прибегает к собственным (с соавторами) прогнозам, учитывающим не только рождаемость и смертность, но и миграцию. За оптимальный сценарий почитается рост рождаемости, приводящий к росту численности населения почти до 155 млн человек. И на этом основании автор делает вывод, что «цена принимаемых сегодня решений - это жизни более 50 млн наших соотечественников» [выделено автором - A.T.]. Это очередное заблуждение недемографов (правда, его разделяют, к сожалению, и некоторые «демографы»), которые относят аборты или детей, не рожденных по вынужденным обстоятельствам (кризис, резкое ухудшение условий жизни семьи, падение уровня жизни всего населения или молодых семей и др.) к якобы реальным потерям 
населения, приравнивая нерождение к смерти человека. И в устном, и в письменном докладах автор часто говорит о сверхсмертности населения, не указывая конкретно, что он имеет в виду. Этот термин, введенный в отечественную науку Б.Ц. Урланисом [Демографическая энциклопедия 2013: 873], имел вполне конкретный смысл: речь шла о повышенной смертности мужчин, особенно трудоспособного возраста, по сравнению с женщинами. Автор, по-видимому, имеет в виду что-то иное, он ни разу не упоминает, что речь идет о мужском населении, просто говорит о сверхсмертности в России и о возможном приросте населения, связанном с ее возможной ликвидацией.

С.Ю. Малков (Институт экономики РАН, факультет глобальных процессов МГУ) на примере Японии рассмотрел стадии индустриального и демографического развития, а затем перенес эти закономерности на страны БРИКС. По его мнению, страны БРИКС идут за западными странами, догоняют их. На основе концептуальных положений теории демографического перехода докладчик предложил выделить страны периферии, отличительной особенностью которых являются низкие темпы демографического (именно так - на первом месте) и экономического развития. В странах БРИКС, по его мнению, произошла «локальная глобализация». Не совсем понятно, что при этом имеется в виду, так как эти страны являются географически оторванными друг от друга (кроме Китая и России) и входящими в другие интеграционные объединения, которые не мешают, а способствуют их все большему вовлечению в процессы глобализации.

Весьма интересной оказалась постановка вопроса в выступлении А.И. Агеева (генеральный директор Института экономических стратегий), также одного из авторов письменного доклада. Как бы перекликаясь с выступлением А.В. Коротаева, который главной причиной высокой смертности в России считает высокую алкоголизацию ее населения (об этом много и плодотворно писал А.В. Немцов), он подчеркнул, что уровень смертности зависит и от низкого уровня жизни, и от большой доли населения, живущего за чертой бедности, относя эту постановку вопроса в первую очередь к России. В этой связи он задал вполне правомерный вопрос: кто мы в процессе будущего восхождения цивилизации Востока? Приходится еще раз сожалеть об отсутствии дискуссии на столь дискуссионном форуме, где авторы общего доклада не имеют единой точки зрения. В то же время это свидетельствует, на наш взгляд, о больших возможностях отечественных научных школ внести свой вклад в анализ и поиск наиболее подходящих моделей развития стран БРИКС, которые, разумеется, будут оставаться разными в демографическом, социальном, экологическом отношениях еще длительное время, несмотря на устойчивый (кроме России и ЮАР) рост ВВП.

Все выступающие (например, кроме уже названных, Д.К. Чистилин, С.Ю. Глазьев, А.В. Островский - последний предложил принять государственную программу развития талантов) говорили о показателе ожидаемой продолжительности жизни только в среднем, не понимая важности или не упоминая о больших различиях между этим показателем у мужского и женского населения не только России, но и других стран БРИКС. Даже в Китае, где полвека назад ситуация была противоположной, разрыв между этими показателями в последнее межпереписное десятилетие возрос, о чем свидетельствуют опубликованные в Китае данные (таблица). 
Ожидаемая продолжительность жизни, рассчитанная с использованием данных трех переписей населения

\begin{tabular}{c|c|c|c|c|c|c|c|c}
\hline \multirow{2}{*}{ Год } & \multicolumn{2}{|c|}{ Китай } & \multicolumn{2}{c|}{ Пекин } & \multicolumn{2}{c}{ Шанхай } & \multicolumn{3}{c}{ Чунцин } \\
\cline { 2 - 9 } & мужчины & женщины & мужчины & женщины & мужчины & женщины & мужчины & женщины \\
\hline 1990 & 66,84 & 70,47 & 71,07 & 74,93 & 72,77 & 77,02 & - & - \\
2000 & 69,63 & 73,33 & 74,33 & 78,01 & 76,22 & 80,04 & 69,84 & 73,89 \\
2010 & 72,38 & 77,37 & 78,28 & 82,21 & 78,20 & 82,44 & 73,16 & 78,60 \\
\hline
\end{tabular}

Источник: [China Statistical Yearbook 2013]

В заключение можно отметить, что демографическая составляющая является, без сомнения, «ахиллесовой пятой» российских исследователей стран БРИКС, поэтому ученые-демографы должны внести свой вклад в эти исследования, тем самым показав вполне достойный уровень отечественной демографии.

\section{ЛИТЕРАТУРА}

Демографическая энциклопедия (2013) / Гл. ред. А.А. Ткаченко. М.: ООО "Издательство "Энциклопедия".

Перспективы и стратегические приоритеты восхождения БРИКС (2014). Научный доклад к VII саммиту БРИКС / Под редакцией В. А. Садовничего, Ю.В. Яковца, А.А. Акаева. М.: МИСК-ИНЭС-НКИ БРИКС.

China Statistical Yearbook (2013). National Bureau of Statistics of China. URL: http://www.stats.gov.cn/tjsj/ndsj/2013/indexeh.htm (дата обращения: 01.09.2014). 


\section{ON DEMOGRAPHIC DEVELOPMENT OF THE BRICS COUNTRIES}

\section{Notes from the Civilizational Forum "Perspectives and strategic priorities for BRICS ascension"}

\section{ALEXANDER TKACHENKO}

Alexander Tkachenko, Financial University under the Government of the Russian Federation. Russia. E-MAIL alaltkachenko@gmail.com; AATkachenko@fa.ru

DATE RECEIVED: DECEMBER 2014.

The article looks at the results of the Civilizational Forum "Perspectives and strategic priorities for BRICS ascension", which discussed a report for the upcoming 7th BRICS summit in 2015 in the city of Ufa, Russia. The author focuses on the two main issues of the published report: (1) the demographic forecast for the BRICS countries up to 2100, and (2) the idea of an opposition between the civilizations of the declining West and the rising East. The models of population growth presented at the Forum are too provisional, do not take into account migration and yet provide recommendations to the governments of the two largest countries in the world. According to the report, the main threat to India is that of exceeding the ecological capacity of its territory if the current rate of population growth is sustained. China, on the contrary, must increase its fertility if it is to solve the problems of population ageing and the consequent drop in the share of the workforce after 2050. These and some other ideas of the report, in the author's opinion, contradict contemporary concepts of demographic science.

Key words: BRICS as a geocivilizational union, population forecast, world civilizations, life expectancy, geopolitical potential, human capital, labor productivity.

\section{REFERENCES}

China Statistical Yearbook (2013). National Bureau of Statistics of China. URL: http://www.stats.gov.cn/tjsj/ndsj/2013/indexeh.htm (date accessed: 01.09.2014).

Demograficheskaya entsiklopediya [Demographic Encyclopedia] (2013) / A. Tkachenko, eds. M.: OOO "Izdatel'stvo "Entsiklopediya".

Perspektivy i strategicheskiye prioritety voskhozhdeniya BRIKS [Prospects and strategic priorities for the rise of the BRICS] (2014). Nauchnyy doklad k VII sammitu BRIKS [Scientific report to the VII summit of BRICS] / V. A. Sadovnichiy, Yu.V. Yakovets, A.A. Akayev, eds. M.: MISK-INES-NKI BRIKS. 